\section{Factor rotation in interactive BASIC}

\section{GALE A. WILSON and WILLIAM A. FREDERICKSON Central State University, Edmond, Oklahoma 73034}

An interactive BASIC computer program is presented to accomplish the quartimax and normalized varimax rotation of a factor loading matrix. The program is designed for use with small computers, allowing easier access and less expensive operation than is usually associated with "batch" processing and large computers.

A recent paper by Schmitt (1977) includes a BASIC computer program that quickly completes a factor analysis (centroid method) but is dependent on "canned" programs and large computers to rotate the resulting factor matrix to a more meaningful "simple structure." We needed a rotation program to take advantage of BASIC's easier access for laboratory use and to allow individuals with minimum computer expertise to utilize and explore this method of data analysis.

The program follows the general logic of Kaiser (1959). The technique suggested by Harmon (1976) has been substituted for calculating the proper angle of rotation. Although normalized varimax and quartimax are presented in this paper, computational methods for all orthogonal rotations are similar, and the program can be modified with other methods not yet as popular, such as equimax and biquartimax.

Input, Output, and Limitations. The program was written on a PDP-11/45 Digital Equipment Corporation timeshare system and requires $15 \mathrm{~K}$ of main memory with the present dimension statements. Adapting the program to run on other machines should not be a problem, since the only departure from common BASIC is the exclusion of "LET" in the assignment statements.

Input to the program is a factor loading matrix; it is facilitated by a routine that allows the user to correct errors made during data entry, and it checks to make sure that all entries are less than one. In its present form, the program handles up to 70 variables and 30 factors, although it may be altered to meet specific needs, since the dimensions are interdependent. The convergence criterion is set at .001 , and in the event of nonconvergence, the rotation of factors ceases after the 20th iteration. Output includes the rotated factor loadings, communalities, and the variance explained by each factor.

Availability. A program listing and sample input and output can be obtained at no charge by writing William A. Frederickson, Department of Psychology, Central State University, 100 North University, Edmond, Oklahoma 73034.

\section{REFERENCES}

HaRmon, H. H. Modern factor analysis (3rd ed.). Chicago: University of Chicago Press, 1976.

KAISER, H. F. Computer program for varimax rotation in factor analysis. Educational and Psychological Measurement, 1959, $19,413-420$.

Sснмітт, J. C. Factor analysis in BASIC for minicomputers. Behavior Research Methods \& Instrumentation, 1977, 9, 302-304.

(Accepted for publication April 10, 1980.) 